\title{
Factors Affecting Forging Process in Steel 1018
}

\author{
Godwin Barnabas.s \\ Velammal College of \\ Engg. \& Tech. \\ Madurai, Tamilnadu \\ Prabhakaran.R \\ Velammal College of \\ Engg. \& Tech. \\ Madurai, Tamilnadu \\ Satheeshkumaran T \\ Velammal College of \\ Engg. \& Tech. \\ Madurai, Tamilnadu \\ Janarthanan.S \\ Velammal College of \\ Engg. \& Tech. \\ Madurai, Tamilnadu
}

\begin{abstract}
Forging is the working of metal into a useful shape by hammering or pressing. This is a oldest of the metal working art (primitive blacksmith).Replacement of machinery occurred during early the Industrial revolution. Most forging operations are carried out hot, although certain metals may be cold-forged. In this paper we are going to see the process parameters that affect forging. And also the solution for improving the process to increase the productivity.
\end{abstract}

Key words: parameters, forging, process, productivity, effect

\section{INTRODUCTION:}

This paper provides fundamental process parameters that affect forging. And the mathematical approaches used in the calculation required to improve the final product. Classification of process parameters that affects forging is also provided with descriptions of defects observed from the forging processes.The solutions to tackle such defects will also be addressed.Forging is the working of metal into a useful shape by hammering or pressing. The oldest of the metal working arts(primitive blacksmith).Replacement of machinery occurred during early the Industrial revolution. Forging machines are now capable of making parts ranging in size of a bolt to a turbine rotor. Most forging operations are carried out hot, although certain metals may be cold-forged. Drawing Is used to reduce the cross-sectional area of the work piece with concurrent increase in length. Piercing and punching are used to produce holes in metals. in forging the load was calculated without considering the friction. But there will be a small amount of friction due to the interface between work piece and the material. If we consider the friction in load calculation we can get a better output.

\section{LITERATURE:}

M. Irani1, A. KarimiTaheri*[1]Precision forging is a suitable process to produce spur gears due to its advantages such as reduction in machining time and production cost. The homogeneity in microstructure and mechanical properties of precision forging products can highly affect the performance of the gears during their service. In this research the effect of precision forging temperature on homogeneity of microstructure and hardness of forged gears of low carbon steel is studied. The microstructure and hardness map of the gears forged at a temperature range of $750-1150{ }^{\circ} \mathrm{C}$ revealed that the forging temperature of $950{ }^{\circ} \mathrm{C}$ is an optimum temperature to produce a spur five teeth gear with minimum inhomogeneity in the microstructure and hardness distribution.

S. B. Mehta\#1, D. B. Gohil\#2[2]The computational modeling and simulation of forging process is now well established. But finite element (FE) analysis of forging process generally takes a long time to carry out. Also it requires a particular skill set from its user. The main objective of this document is to discuss the analytical methods for measuring parameters such as load, and stress distribution of forging process and use them to make a simple, reliable, fast and non-expensive simulation tool, with a GUI, contrary to the commercial software's which require much means, time and a perfect knowledge of the process. Of the various methods used for analysing forging operations, the most often us

often used SLAB method techniques are described here.

M.K.A. Ariffin A.A. Faieza[3]The objective of this paper is to obtain an optimal billet shape in the considerationof the influence of the metal flow deformation in closed die forging process. Finite elementmethod in conjunction with optimization algorithm was used to analyze the effect of billetshape on forging load in axisymmetric closed die forging process. Finite element software(ANSYS) was used to simulate closed die forging process and then performing a series ofoptimization iterations in order to obtain the optimal shape of the billet based on forgingload minimization. The material used is aluminium metal matrix composite (AlMgSimatrix with $15 \% \mathrm{SiC}$ particles). The goal of the simulation and optimization process is tominimize the forging load and produce crack-free forgings. The optimal shape of the billetthat gives minimum forging load was obtained after several optimization iterations. Theapproach used in this study could be extended to the optimization of more complicatedforging products.

O. Barraua, C. Bohera,*, R. Gras b, F. Rezai-Aria a[4]A significant part of the energy in forging is used to break the interfacial junctions due to friction between the tool and the workpiece. The life of hot-forging tools is usually limited by complex interactive mechanisms under 
cyclic loading such as abrasive, adhesive and scaling wear, thermal and mechanical fatigue, and plastic deformation.This contribution deals with the wear mechanisms of the tempered martensitic X38CrMoV5 steel (AISI H11) under high-temperatureand dry-sliding wear. The investigations are carried out with high-temperature pin-on-disc tests. The pin is cut from bars of X38CrMoV5 steel treated at 42 and $47 \mathrm{HRC}$. The disc is made of common steel (AISI 1018, XC18). Temperature of the disc ranges from 20 to $950{ }^{\circ} \mathrm{C}$. Before the test starts, the disc is first pre-heated for $1 \mathrm{~h}$. The experiments are performed under constant load and velocity. The friction coefficient decreases quasi-linearly with the rising disc temperature up to800 ${ }^{\circ} \mathrm{C}$. Over this temperature, it decreases drastically for the 42HRC steel but remains linear for the 47HRC steel. Scanning electron microscopy (SEM) and energy dispersive spectrometry (EDS) investigations have revealed that wear is essentially due to abrasion, plastic deformation and fatigue. Set of cracks due to contact rolling fatigue is observed on the pin and the disc. Those cracks are located on the transferred scale on the pin and on the oxide scale of the disc wear track. The cross-section observations of the pin have revealed a plastically deformed zone beneath the surface. In this sub-surface layer, the tempered martensitic microstructure seems to be more aligned due to friction and the plastic deformation. Alloy 1018 is the most commonly available of the cold-rolled steels. It is generally available in round rod, square bar, and rectangle bar. It has a good combination of all of the typical traits of steel - strength, some ductility, and comparative ease of machining. Chemically, it is very similar to A36 Hot Rolled steel, but the cold rolling process creates a better surface finish and better properties.

\section{EXPERIMENTAL DESIGN WITH TAGUCHI METHOD:}

The Taguchi method involves reducing the variation in a process through robust design of experiments. The overall objective of the method is to produce high quality product at low cost to the manufacturer. The Taguchi method was developed by Dr. Genichi Taguchi of Japan who maintained that variation. Therefore, poor quality in a process affects not only the manufacturer but also society. Method for designing experiments to investigate how different parameters affect the mean and variance of a process performance characteristic that defines how well the process is functioning. The experimental design proposed by Taguchi involves using orthogonal arrays to organize the parameters affecting the process and the levels at which they should be varied; it allows for the collection of the necessary data to determine which factors most affect product quality with a minimum amount of experimentation, thus saving time and resources. Analysis of variance on the collected data from the Taguchi design of experiments can be used to select new parameter values to optimize the performance characteristic. In this article, the specific steps involved in the application of the
Taguchi method will be described and examples of using the Taguchi method to design experiments will be given.

Table : 1 process parameters with levels

\begin{tabular}{|l|l|l|l|}
\hline Parameter & Level 1 & Level 2 & Level 3 \\
\hline $\begin{array}{l}\text { Temperature } \\
\left({ }^{\circ} \mathrm{c}\right)\end{array}$ & 1800 & 1700 & 1600 \\
\hline Pressure (N/M) & $2.45 \mathrm{E} 6$ & $2.39 \mathrm{E} 6$ & $2.29 \mathrm{E} 6$ \\
\hline Friction factor & 0.63 & 0.53 & 0.44 \\
\hline
\end{tabular}

An array's name indicates the number of rows and columns in the as, and also the number of levels in each of the columns. Thus, the array $\left(\operatorname{Lg}_{9}{ }^{4}\right)$ has nine rows and four columns of three levels. With the selection of $\left(\mathrm{L}_{9} 3^{4}\right)$ orthogonal array, using four parameters and three levels for each, the number of experiments required can be drastically reduced to nine, which in classical combination method using full factorial experimentation would require $3^{4}=81$ number of experiments to capture the influencing parameters. The SSF process parameters namely Forging Temperature (A), percent reduction (B) and die preheating temperature $(\mathrm{C})$ are assigned to the first, second and third columns of $\left(\mathrm{L93}{ }^{4}\right)$ array, respectively.

\section{CONDUCT OF THE EXPERIMENTS AND DATA COLLECTION}

A steel 1018,popular in industrial products, is used for the investigation of mechanical properties The plate type conventional casting sample was cut into dimensions $100 \times 60 \times 40 \mathrm{~mm}^{3}$. The next step in Taguchi method is to conduct the experiments. A 150tons capacity hydraulic Press is employed for the application of pressure. The experimental setup is shown in Figure. These samples were heated in a resistance-heating furnace at temperature ranges between $1600^{\circ} \mathrm{C}$ to $1800^{\circ} \mathrm{C}$ for 45 minutes of soaking time. Before forging the die setup of the Hydraulic Press was pre-heated to the temperature ranges between $150^{\circ} \mathrm{C}$ to $250{ }^{0} \mathrm{C}$ as per Taguchi design of experiments. Forging is performed with the help of Hydraulic press with different reduction in the thickness of the each sample as per Taguchi design data sheet of $\left(\mathrm{L} 93^{4}\right)$ OA for each trial condition and they are shown in Figure. Then the forged samples were cooled in atmosphere for 2 hours. Test specimens carved out of these samples. Surface hardness data values are collected from each specimen at four locations. The surface hardness values for nine trial conditions with four measurement locations have been recorded. These values along with the average response values are shown in Table2. 
Fig1: hydraulic press

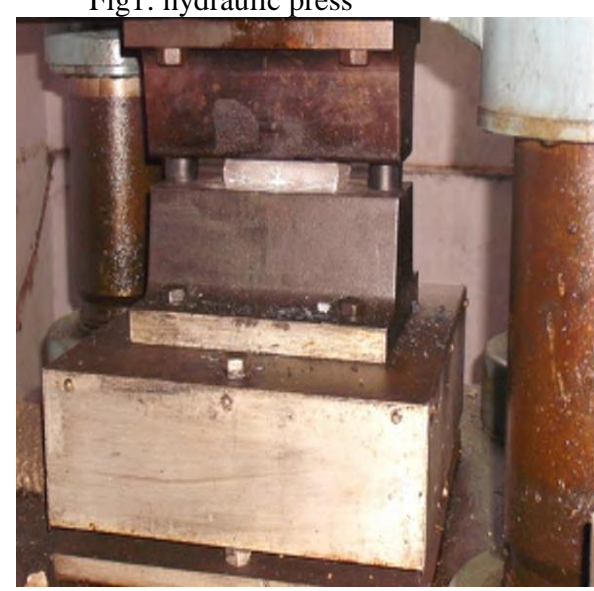

$\mathrm{SN}_{\mathrm{i}}=10 \log \underline{\mathrm{y}^{2}}$

$$
\begin{gathered}
\mathbf{S}_{\mathrm{i}}{ }^{2} \\
\mathbf{S}_{\mathrm{i}}{ }^{2}=\frac{\mathbf{1}}{N i-1}{ }_{u=1}^{N i} y i u-y i \\
\bar{Y}_{\mathrm{i}}=\frac{1}{N i} \quad{ }_{U=1}^{N i} y i, u
\end{gathered}
$$

Where

$\mathrm{i}=$ experiment number

\begin{tabular}{|c|c|c|c|c|c|c|c|c|}
\hline \multirow[t]{2}{*}{$\mathbf{N}$} & \multicolumn{3}{|c|}{$\begin{array}{l}\text { PARAMETERS } \\
\text { ASSINMENT }\end{array}$} & \multicolumn{3}{|c|}{ HARDNESS (BHN) } & \multirow[t]{2}{*}{$\begin{array}{l}\text { AVG } \\
\text { (BHN) }\end{array}$} & \multirow[t]{2}{*}{$\begin{array}{l}\text { S/N } \\
\text { RATIO }\end{array}$} \\
\hline & $\mathbf{A}$ & B & C & 1 & 2 & 3 & & \\
\hline 1 & 1800 & $2.45 \mathrm{E} 6$ & 0.63 & 117.9 & 117.6 & 116.3 & 117.2 & 42.7 \\
\hline 2 & 1800 & 2.39E6 & 0.53 & 117.7 & 116.4 & 117.1 & 117.0 & 45.4 \\
\hline 3 & 1800 & 2.29E6 & 0.44 & 117.9 & 116.7 & 117.5 & 117.3 & 30.8 \\
\hline 4 & 1700 & $2.45 \mathrm{E} 6$ & 0.53 & 116.3 & 117.1 & 116.2 & 116.5 & 47.3 \\
\hline 5 & 1700 & 2.39E6 & 0.44 & 115.9 & 115.8 & 116.1 & 115.9 & 34.72 \\
\hline 6 & 1700 & $2.29 \mathrm{E} 6$ & 0.63 & 115.7 & 116.6 & 115 & 115.7 & 43.17 \\
\hline 7 & 1600 & $2.45 \mathrm{E} 6$ & 0.44 & 115.9 & 115.7 & 116.1 & 115.9 & 55.26 \\
\hline 8 & 1600 & 2.39E6 & 0.53 & 114.7 & 114.9 & 115.6 & 115.0 & 41.21 \\
\hline 9 & 1600 & 2.29E6 & 0.63 & 114.1 & 114.1 & 115.9 & 114.7 & 41.30 \\
\hline
\end{tabular}

$\mathrm{N}_{\mathrm{i}}=$ number of trial for experiment $\mathrm{i}$

$\mathrm{U}=$ trial number

Table2:Results of (L9) Orthogonal Array Experiments
Table 3: Average response for raw data

\begin{tabular}{|c|c|c|c|}
\hline Levels & $\begin{array}{c}\text { A: Forging } \\
\text { Temp. }\end{array}$ & B: load & C: friction \\
\hline 1 & 115.1 & 116.0 & 116.4 \\
\hline 2 & 116.2 & 116.0 & 116.1 \\
\hline 3 & 117.1 & 116.0 & 116.0 \\
\hline $\begin{array}{c}\text { Maxi } \\
\text { mum- }\end{array}$ & 2.0 & 0.6 & 0.4 \\
\hline Rank & 1 & 2 & 3 \\
\hline
\end{tabular}

Where $\mathrm{n}$ is the number of measurements in a trial (here $\mathrm{n}=3$ ) and $\mathrm{y}_{\mathrm{i}}$ is the $\mathrm{i}^{\text {th }}$ response for each noise repetition

ANOVA computation is performed for evaluating the significance of the process parameters over hardness. Table 3 and Table4 show the average effect response for raw data and $\mathrm{S} / \mathrm{N}$ ratio. From Table5 it is observed that percent reduction is the most significant factor for the response hardness.

Table4:Average Effect Response for S/N Ratio

\begin{tabular}{|l|l|l|l|}
\hline Levels & A: ForgingTemp. & B: \%load & C:friction \\
\hline 1 & 48.10 & 43.39 & 52.85 \\
\hline 2 & 49.42 & 50.15 & 44.63 \\
\hline 3 & 45.52 & 48.51 & 44.57 \\
\hline $\begin{array}{l}\text { Maximum- } \\
\text { Minimum }\end{array}$ & 4.90 & 6.75 & 8.28 \\
\hline Rank & 3 & 2 & 1 \\
\hline
\end{tabular}

Table5: Computation of ANOVA

\begin{tabular}{|l|l|l|l|}
\hline Levels & $\begin{array}{l}\text { A: Forging } \\
\text { Temp. }\end{array}$ & B: \%load & C:friction \\
\hline 1 & 48.10 & 43.39 & 52.85 \\
\hline 2 & 49.42 & 50.15 & 44.63 \\
\hline 3 & 45.52 & 48.51 & 44.57 \\
\hline $\begin{array}{l}\text { Maximum- } \\
\text { Minimum }\end{array}$ & 4.90 & 6.75 & 8.28 \\
\hline Rank & 3 & 2 & 1 \\
\hline
\end{tabular}




\section{RESPONSE GRAPHS}

The response graphs exhibit a pictorial view of variation of each parameter and describe what the effect on the system performance

would be, when a parameter shifts from one level to another. Figure 3 shows response for hardness for all the parameters. Figure4 shows response for $\mathrm{S} / \mathrm{N}$ ratio, as an example, level two for percent reduction $\left(\mathrm{B}_{2}=60 \%\right)$ has the highest $\mathrm{S} / \mathrm{N}$ ratio value, which indicates that the SSF performance at such level produces minimum variation of the response hardness.

\section{Fig:3 main effects}

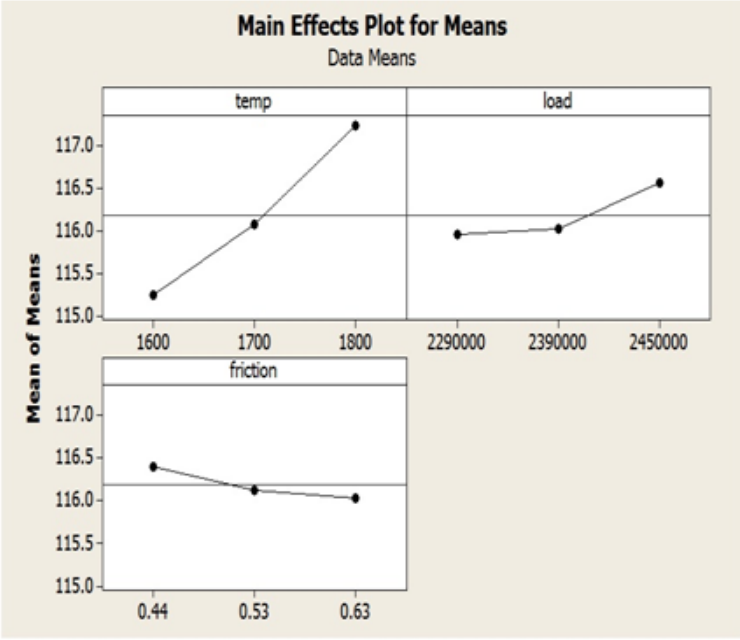

Fig:4 S/N ratio

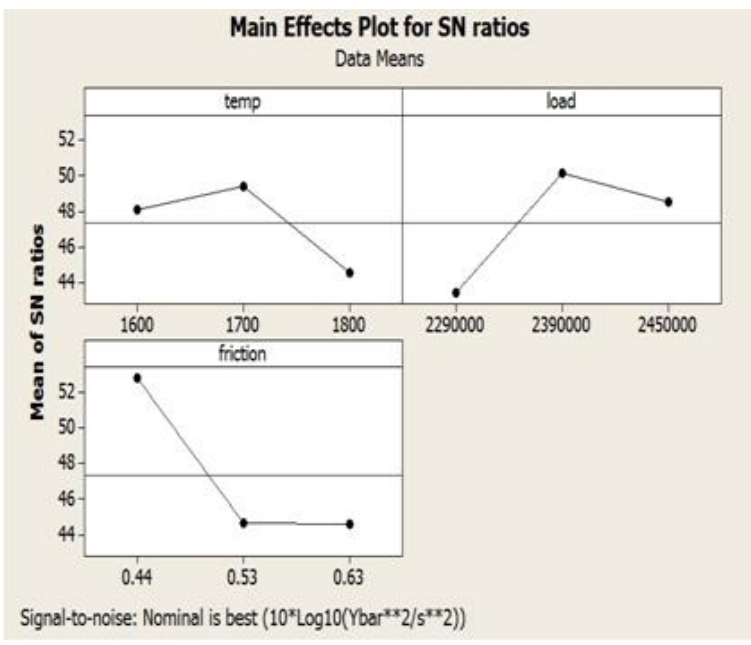

\section{Fig:5 histogram 1}

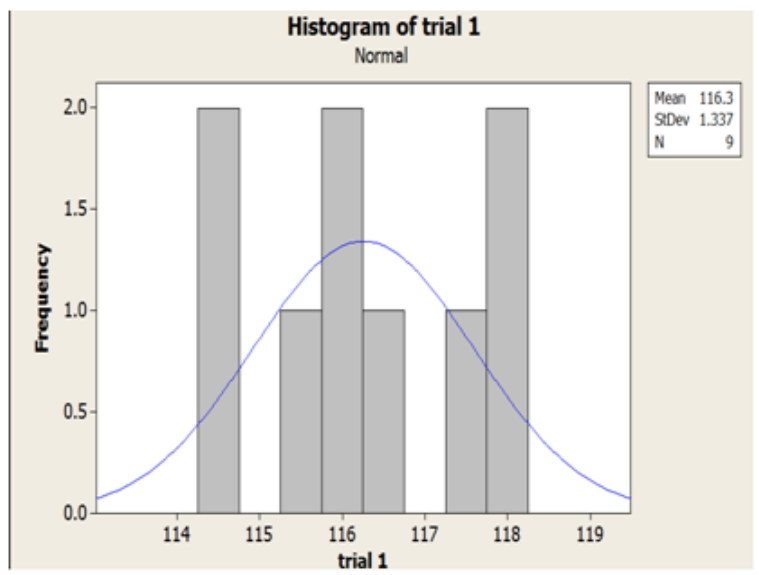

Fig:6 histogram of trial 2

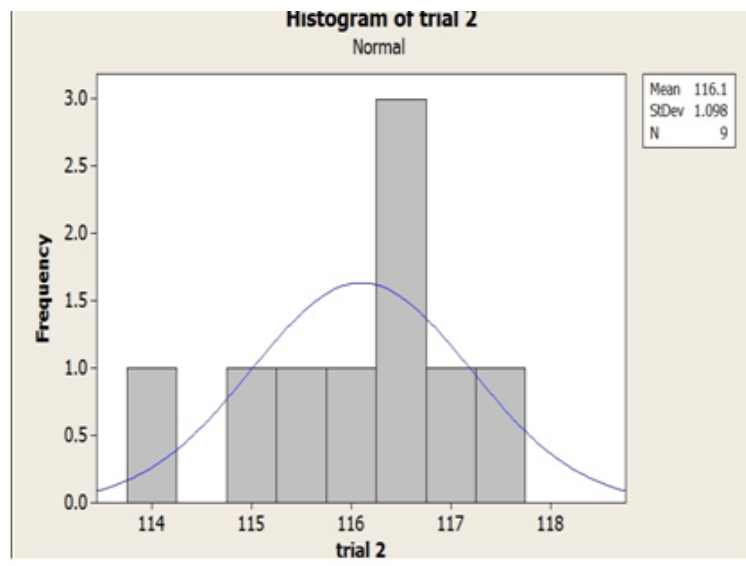

Fig :7 histogram of trail 3

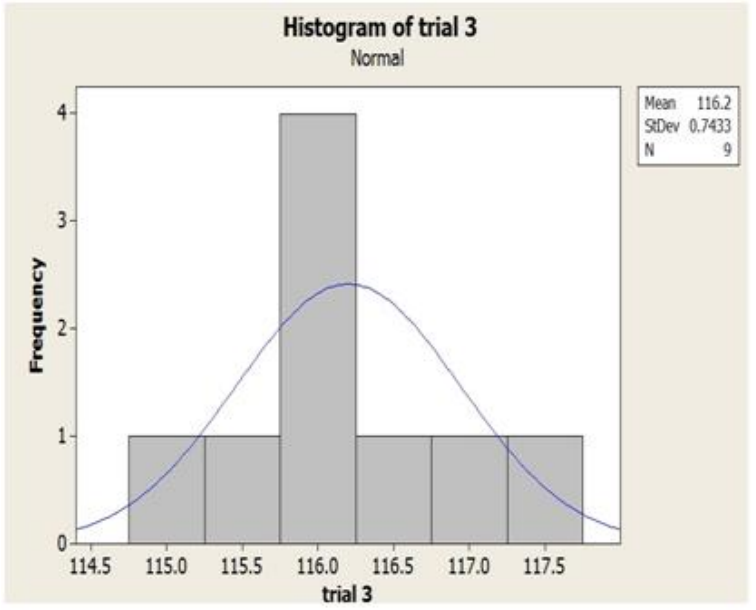


Fig:8 3D graph

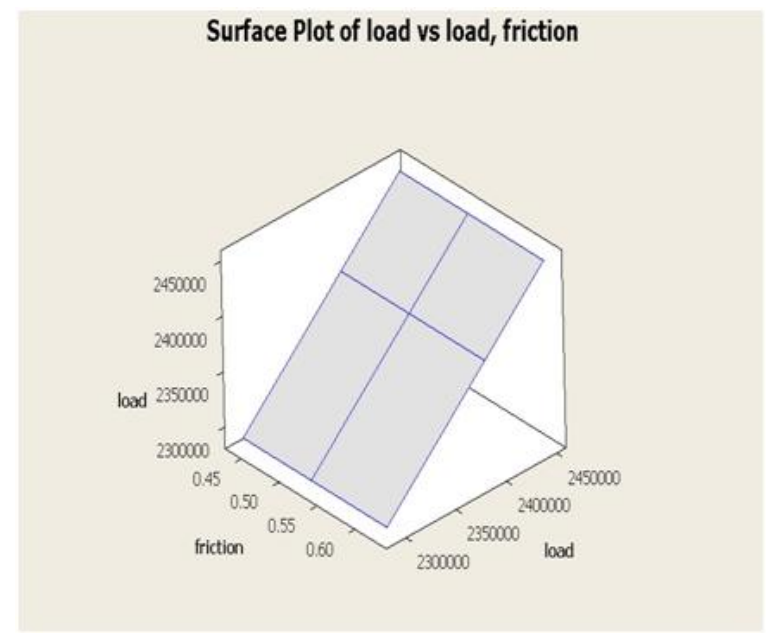

\section{CONCLUSION}

The optimum level of process parameter to obtain maximum hardness of SSF components of steel 1018 are A3, B2, C2 From the response graph for hardness and S/N ratio, and ANOVA Table, it reveals that the percent reduction is a major contributing factor to wards the improvement of hardness of steel 1018 . As the pressure is applied during SSF, It forced the metal to accommodate closely to the die surface, thereby paving the way for the components to exhibit improved hardness. During this research, only three factors namely forging temperature, load and friction between die and work piece were considered. Significant scope exists to design and conduct further experiments for determining the exhaustive combination of factor sand levels by including parameters like forging pressure, strain rate and time of applying pressure. These findings would enable the production of SSF components with higher degrees of hardness and mechanical properties.

\section{REFERENCES}

[1]Sirong,Yu.; cheng,L.D.; Kim,N.(2006): Microstructure Evolution of SIMA Processed A12024, Materials Science and Engineering A, 420,pp.165-170.

[2] Fan,Z. (2002): Semi-Solid Metal Processing, Int. Mater. Rev.,47, pp.49-85.

[3] Kirkwood,D.H. (1994):Semi-Solid Metal Processing, Int. Mater .Rev.,39,pp.173-189.

[4] Sang-Yong,L.: Jung-Hwan,L.: YoungSeon,L. (2001): Characterisation of A7075 Alloys after Cold Working and Heating in the Semi-Solid Temperature Range, Journal of Materials Processing Technology, 111,pp.42-47. 